\title{
Substrate binding modes and anomer selectivity of chitinase A from Vibrio harveyi
}

\author{
Wipa Suginta $\cdot$ Supansa Pantoom $\cdot$ Heino Prinz
}

Received: 26 February 2009 /Accepted: 7 May 2009 / Published online: 28 May 2009

(C) Springer-Verlag 2009

\begin{abstract}
High-performance liquid chromatography mass spectrometry (HPLC MS) was employed to assess the binding behaviors of various substrates to Vibrio harveyi chitinase A. Quantitative analysis revealed that hexaNAG preferred subsites -2 to +2 over subsites -3 to +2 and pentaNAG only required subsites -2 to +2 , while subsites -4 to +2 were not used at all by both substrates. The results suggested that binding of the chitooligosaccharides to the enzyme essentially occurred in compulsory fashion. The symmetrical binding mode $(-2$ to +2$)$ was favored presumably to allow the natural form of sugars to be utilized effectively. Crystalline $\alpha$ chitin was initially hydrolyzed into a diverse ensemble of chitin oligomers, providing a clear sign of random attacks that took place within chitin chains. However, the progressive degradation was shown to occur in greater extent at later time to complete hydrolysis. The effect of the reducing-end residues were also investigated by means of HPLC MS. Substitutions of Trp275 to Gly and Trp397 to Phe significantly shifted the anomer selectivity of the enzyme toward $\beta$ substrates. The Trp275 mutation modulated the kinetic property of the enzyme by decreasing the catalytic constant $\left(k_{\text {cat }}\right)$ and the substrate specificity $\left(k_{\text {cat }} / K_{\mathrm{m}}\right)$ toward all substrates by five- to tenfold. In contrast, the Trp397
\end{abstract}

\footnotetext{
W. Suginta $(\bowtie) \cdot$ S. Pantoom

Biochemistry-Electrochemistry Research Unit,

School of Chemistry and Biochemistry, Institute of Science,

Suranaree University of Technology,

Nakhon, Ratchasima 30000, Thailand

e-mail: wipa@sut.ac.th

H. Prinz

The Max-Planck Institute of Molecular Physiology,

Otto-Hahn-Strasse 11,

44227 Dortmund, Germany
}

mutation weakened the binding strength at subsite (+2), thereby speeding up the rate of the enzymatic cleavage toward soluble substrates but slowing down the rate of the progressive degradation toward insoluble chitin.

Keywords Chitin - Substrate binding mode - HPLC MS . Vibrio harveyi $\cdot$ Family-18 chitinase $\cdot$ Active-site mutation

\begin{tabular}{|c|c|}
\hline \multicolumn{2}{|c|}{ Abbreviations } \\
\hline $\mathrm{NAG}_{n}$ & $\begin{array}{l}\beta-1-4 \text { linked oligomers of } N \text {-acetylglucos- } \\
\text { amine residues where } n=1-6\end{array}$ \\
\hline DNS & Dinitrosalicylic acid \\
\hline IPTG & Isopropyl thio- $\beta$-D-galactoside \\
\hline PMSF & Phenylmethylsulfonylfluoride \\
\hline $\begin{array}{l}\text { HPLC ESI- } \\
\text { MS }\end{array}$ & $\begin{array}{l}\text { High-performance liquid chromatography } \\
\text { electrospray mass spectrometry }\end{array}$ \\
\hline ChBD & Chitin-binding domain \\
\hline
\end{tabular}

\section{Introduction}

Chitin is a homopolymer composed of $\beta$-(1,4)-linked $N$ acetylglucosamine (GlcNAc or NAG) units and is mainly found as a structural component of fungal cell walls and exoskeletons of crustaceans and insects. A complete degradation of chitin requires chitinases (EC 3.2.1.14) and $N$-acetyl- $\beta$-glucosaminidases (EC 3.2.1.52). Chitinases are found in various organisms, and their physiological functions are dependent on the structural roles of chitin substrates existing in different species. Degradation of chitin by marine bacteria $[1,2]$ is crucial for maintaining the ecosystem in the marine environment [3]. In insects, chitinases are essential in the molting process and may also affect gut physiology through their involvement 
in peritrophic membrane turnover [4]. Plants produce chitinases as part of their defense mechanism against distinct pathogens $[5,6]$, whereas fungal chitinases participate in a number of morphogenetic processes, including spore germination, side-branch formation, differentiation into spores, and autolysis [7]. Human chitinases are involved in asthma and inflammatory conditions, but the endogenous substrate(s) and the pathogenic mechanism is not yet known [8-10].

Different bacteria seem to secrete different forms of chitinases [2, 11-17]. For example, Serratia marcescens produces three chitinases: $\mathrm{ChiA}, \mathrm{ChiB}$, and $\mathrm{ChiC}$ for a synergistic degradation of chitin $[18,19]$, whereas Vibrio harveyi (formerly Vibrio carchariae) mainly expresses chitinase A [2]. In the CAZy database (http://www.cazy. org), $V$. harveyi chitinase $\mathrm{A}$ is classified as a member of family-18 glycosyl hydrolases, comprising a $(\beta / \alpha)_{8}$-barrel catalytic domain with a deep substrate-binding cleft and is known to catalyze the hydrolytic reaction through the 'substrate-assisted' or 'retaining mechanism' [20-26]. Most recently, the crystal structures of $V$. harveyi chitinase and its mutant $\mathrm{E} 315 \mathrm{M}$ complexed with $\mathrm{NAG}_{5}$ and $\mathrm{NAG}_{6}$ were reported at 1.8-2.1 $\AA$ resolutions [27]. The structures revealed that chitooligosaccharides most likely interact with the multiple subsites of the enzyme using a linear conformation. Subsequently, the sugar chain develops a 'kink' conformation to facilitate bond cleavage. Such a movement is presumed to proceed via the 'slide and bend' mechanism [27]. The sliding motion of a chitooligomer resembles the feeding mechanism proposed by Watanabe and co-workers [28] for long-chain chitin. Either sliding or feeding, the process could be achieved only when a chitinase exhibits high processivity toward its substrates. The processivity has been described previously for other polysaccharide degrading enzymes, such as Chi A from $S$. marcescens [19, 28-30], cellobiohydrolases Cel6A from Humicola insolens [31], and Cel7A from Trichoderma reesei [32].

Insoluble substrates have been proposed to enter the active site of chitinases by the feeding mechanism and chitin oligomers by a random mechanism $[28,33]$. Such a hypothesis probably holds true for most of the cases. However, a major point of concern remains the random cleavage of a chitin polymer by an endo action of chitinase A. We previously verified that $V$. harveyi chitinase A initially degraded insoluble chitins into $\mathrm{NAG}_{2-6}[20,34]$. Indeed, the production of the chitin oligomers other than $\mathrm{NAG}_{2}$ cannot be explained as an outcome of the feeding mechanism. This is because the sliding following progressive degradation of chitin will only give rise to a single species of the product $\left(\mathrm{NAG}_{2}\right)$. In this study, we employed quantitative HPLC-MS as a direct and sensitive tool to investigate the binding behaviors of three different sub- strates. Together with kinetic analysis, we also demonstrated that point mutation of the reducing-end binding residues (Trp275 and Trp397) affected the substrate specificity of the tested substrates and significantly altered the anomer selectivity of $V$. harveyi chitinase A. This enzyme belongs to family-18 chitinases, which are potential drug targets for the treatment of allergic asthma.

\section{Experimental}

Bacterial strains and chemicals

The pQE 60 expression vector harboring the DNA fragment that encodes chitinase A (amino acid residues 22-597, without the 598-850 C-terminal fragment) and Escherichia coli type strain M15 (Qiagen, Valencia, CA, USA) were used for a high-level expression of recombinant chitinases. Chitooligosaccharides were obtained from Seikagaku Corporation (Bioactive Co., Ltd., Bangkok, Thailand). Flake chitin from crab shells was the product of Sigma-Aldrich Pte Ltd. (The Capricorn, Singapore Science Park II, Singapore). Other chemicals and reagents (analytical grade) were obtained from the following sources: reagents for bacterial media (Scharlau Chemie S.A., Barcelona, Spain.); all chemicals for protein preparation (Sigma-Aldrich Pte Ltd., Singapore and Carlo Erba Reagenti SpA, Limito, Italy); and reagents for HPLC-MS measurements (J.T. Baker, Deventer, Holland and LGC Promochem GmbH, Wesel, Germany). Milli-Q water was used for preparations of reaction buffers and for HPLC MS measurements.

\section{Instrumentation}

HPLC was operated on a $150 \times 2.1 \mathrm{~mm} 5 \mu \mathrm{m}$ Hypercarb $^{\circledR}$ column (ThermoQuest, Thermo Electron Corporation, San Jose, CA, USA) connected to an Agilent Technologies 1100 series HPLC system (Agilent Technologies, Waldbronn, Germany) under the control of a Thermo Finnigan LTQ electrospray mass spectrometer. The proprietary program Xcalibur (Thermo Finnigan, Thermo Electron Corporation, San Jose, CA, USA) was used to control and calibrate HPLC ESI/MS. For partial hydrolysis of colloidal chitin, the electrospray MS was conducted under a positive full scan mode with a range of the mass/charge ratio $(\mathrm{m} / \mathrm{z})$ of 200-1,400. Later, the HPLC MS was run under the single ion monitoring mode for improvement of signal/ noise ratios. The selected masses for detection were $\mathrm{m} / \mathrm{z}$ 424.5 for $\mathrm{NAG}_{2}, m / z 627.5$ for $\mathrm{NAG}_{3}, \mathrm{~m} / z 830.3$ for $\mathrm{NAG}_{4}$, $\mathrm{m} / z 1034.16$ for $\mathrm{NAG}_{5}$, and $\mathrm{m} / z 1236.3$ for $\mathrm{NAG}_{6}$. The UV signals were detected by a diode array detector between 200 and $400 \mathrm{~nm}$. 
Site directed mutagenesis

Point mutations were introduced to the wild-type chitinase $A$ DNA that was previously cloned into the pQE60 expression vector by polymerase chain reaction (PCR) technique [20], using the QuickChange Site-Directed Mutagenesis Kit. Mutations of Trp275 to Gly and Trp397 to Phe (so as to create mutants W275G and W397F, respectively) were generated using oligonucleotides synthesized from BioServiceUnit (BSU) (Bangkok, Thailand) The forward oligonucleotide sequence used for mutagenesis of Trp275 to Gly is 5'-CATCTATCGGTGGTGGAACACTTTCTGAC- $3^{\prime}$ and the reverse sequence is $5^{\prime}$-GTCAGAAAGTGTTCCACCACCGATAGATG-3'. For mutagenesis of $\overline{\operatorname{Trp} 397}$ to Phe, the forward sequence is $5^{\prime}$ GACTTCTACGGCGGCTTCAACAACGTTCC- ${ }^{\prime}$ ' and the reverse sequence is $5^{\prime}$-GGAACGTTGTTGAAGCCGCCGTAGAAGTC-3'. Sequences underlined represent the mutated codons. The success of point mutations was confirmed by automated DNA sequencing (BSU, Thailand).

\section{Recombinant expression and purification}

The wild-type chitinase A with a C-terminal hexahistidine sequence was highly expressed in E. coli M15 cells [20]. Chitinase A mutants W275G and W397F were obtained by PCR-based site directed mutagenesis as described by Suginta et al. [35]. For recombinant expression and purification, the freshly transformed cells were grown at $37{ }^{\circ} \mathrm{C}$ in $500 \mathrm{~mL}$ of Luria-Bertani medium containing $100 \mu \mathrm{g} \cdot \mathrm{mL}^{-1}$ ampicillin until $\mathrm{OD}_{600}$ reached 0.6 . Then, the chitinase production was induced by the addition of $0.5 \mathrm{mM}$ IPTG at $25{ }^{\circ} \mathrm{C}$ for $18 \mathrm{~h}$. The cell pellet was harvested by centrifugation, re-suspended in $40 \mathrm{~mL}$ of lysis buffer $(20 \mathrm{mM}$ Tris/HCl buffer, $\mathrm{pH} 8.0$, containing $150 \mathrm{mM}$ $\mathrm{NaCl}, 1 \mathrm{mM}$ PMSF, and $1 \mathrm{mg} \cdot \mathrm{mL}^{-1}$ lysozyme), and then lysed on ice using a Sonopuls Ultrasonic homogenizer with a 6-mm-diameter probe. The supernatant obtained after centrifugation at $12,000 \times \mathrm{g}, 45 \mathrm{~min}$ was applied to a $\mathrm{Ni}$ NTA agarose affinity column $(1.0 \times 10 \mathrm{~cm})($ Qiagen $\mathrm{GmbH}$, Hilden, Germany), washed thoroughly with $5 \mathrm{mM}$ imidazole, then eluted with $250 \mathrm{mM}$ imidazole in $20 \mathrm{mM}$ Tris/HCl buffer, $\mathrm{pH}$ 8.0. An eluted fraction $(10 \mathrm{~mL})$ was subjected to several rounds of membrane centrifugation using Vivaspin20 ultrafiltration membrane concentrators $\left(M_{\mathrm{r}} 10,000\right.$ cutoff, Vivascience AG, Hannover, Germany) for a complete removal of imidazole and for concentrating the proteins. Protein purity was verified on sodium dodecyl sulfate polyacrylamide gel electrophoresis as described by Laemmli [36]. A final concentration of the protein was determined by Bradford's method [37] using a standard calibration curve of bovine serum albumin $(0-25 \mu \mathrm{g})$. The freshly prepared proteins were subjected to functional characterization or stored at $-30{ }^{\circ} \mathrm{C}$.

Partial hydrolysis of chitooligosaccharides by $V$. harveyi chitinase A

Partial hydrolysis of chitooligosaccharides by wild-type was carried out in a $50-\mu \mathrm{L}$ reaction mixture, containing $0.1 \mathrm{M}$ ammonium acetate buffer, $\mathrm{pH} 7.0,500 \mu \mathrm{M}$ substrate, and $100 \mathrm{ng}$ purified enzyme. To minimize isomerization of the anomeric products, the reaction was performed on ice $\left(0{ }^{\circ} \mathrm{C}\right)$ for $3 \mathrm{~min}$, and then a $10-\mu \mathrm{L}$ aliquot was transferred to a $200-\mu \mathrm{L}$ sample vial and immediately subjected to HPLC MS analysis. The sample tray was kept at $4{ }^{\circ} \mathrm{C}$, and the column was operated at $10{ }^{\circ} \mathrm{C}$. A constant flow rate of $0.4 \mathrm{~mL} \cdot \mathrm{min}^{-1}$ was applied with a run time set to $15 \mathrm{~min}$ using a $5-70 \%$ gradient of acetonitrile, containing $0.1 \%$ formic acid. The $\beta / \alpha$ ratios were calculated from the peak areas of the corresponding products using the program Xcalibur and applying an MS Genesis algorithm for peak detection.

Time courses of chitin hydrolysis

Time-course experiments were carried out on ice in a 100$\mu \mathrm{L}$ reaction mixture, containing $0.1 \mathrm{M}$ ammonium acetate buffer, $\mathrm{pH} 7.0,10 \%(w / v)$ crystalline $\alpha$ chitin, and $50 \mathrm{ng}$ purified enzyme. Aliquots of $10 \mu \mathrm{L}$ were taken at $0,3,7$, 20, 30, 60, and $180 \mathrm{~min}$ and analyzed immediately by HPLC MS as described for chitin oligosaccharides. The peak areas, which represent total ion counts of the hydrolytic products, were quantified using the program Xcalibur applying a MS Avalon algorithm for peak detection. Standard calibration curves of NAG moieties were constructed separately from a mixture of oligosaccharide containing $0.2-500 \mu \mathrm{M}$ of $\mathrm{NAG}_{1-6}$. These data points yielded a linear curve of each standard sugar with the $R^{2}$ values of $0.9995-1.0$, thus allowing molar concentrations of chitooligosacharides to be determined with confidence. For the determination of $\beta / \alpha$ contents of the chitooligosaccharide products, the reaction mixture, containing $250 \mathrm{ng}$ purified enzyme in $0.1 \mathrm{M}$ ammonium acetate buffer, $\mathrm{pH} 7.0$, was incubated with $500 \mu \mathrm{M} \mathrm{NAG}_{5}$ or $\mathrm{NAG}_{6}$. Aliquots of a $100-\mu \mathrm{L}$ reaction mixture were taken at specified times and analyzed immediately by HPLC MS. Amounts of $\beta$ and $\alpha$ anomers of the hydrolytic products were derived from the corresponding peak areas using the standard calibration curves constructed as mentioned above.

Steady-state kinetics

Kinetic measurements were determined in a microtiter plate using $\mathrm{NAG}_{5}, \mathrm{NAG}_{6}$, and colloidal chitin as substrates. A 
reaction mixture $(100 \mu \mathrm{L})$, containing $0-500 \mu \mathrm{M}$ substrate and chitinase $(50 \mu \mathrm{g}$ wild type, $250 \mu \mathrm{g} \mathrm{W} 275 \mathrm{G}$, or $0.4 \mu \mathrm{g}$ $\mathrm{W} 397 \mathrm{~F}$ ) in $0.1 \mathrm{M}$ sodium acetate buffer, $\mathrm{pH} 5.5$ was incubated at $37{ }^{\circ} \mathrm{C}$ for $15 \mathrm{~min}$. After boiling to $100{ }^{\circ} \mathrm{C}$ for $3 \mathrm{~min}$, the entire reaction mixture was subjected to the reducing sugar assay using dinitrosalicylic acid (DNS) reagent as described by Miller [38]. For colloidal chitin, the reaction was carried out the same way as the reducing-sugar assay, but concentrations of colloidal chitin was varied from $0 \%$ to $5 \%(w / v)$ and amount of enzyme was used at $150 \mu \mathrm{g}$ wild type, $700 \mu \mathrm{g} \mathrm{W} 275 \mathrm{G}$, or $200 \mu \mathrm{g} \mathrm{W} 397 \mathrm{~F}$. The amounts of the reaction products were determined from a standard curve of $\mathrm{NAG}_{2}(0-500 \mathrm{nmol})$. The kinetic values were evaluated from three independent sets of data using the nonlinear regression function available in GraphPad Prism version 5.0 (GraphPad Software Inc., San Diego, CA).

\section{Results}

Structural evidence of hexaNAG in the catalytic cleft of $V$. harveyi chitinase A

We recently described four crystal structures of $V$. harveyi chitinase A and its catalytically inactive mutant E315M in complex with chitooligosaccharides (PDB codes 3BS8, 3B9A, 3B90, and 3B9E) [27]. Figure 1a is a surface representation of the catalytic domain of the mutant E315M, displaying six units of NAG (yellow) being embedded inside a long, deep-binding groove and interact specifically with various aromatic residues that stretch along the elongated cleft of the enzyme. Figure $1 \mathrm{~b}$ represents a stick model underlying specific interactions between Tyr171 and -4NAG, Trp168 and -3 NAG, Trp275 and Trp570 and -1 to $+1 \mathrm{NAG}$, and Trp397 and Tyr435 with +2NAG. It is clear that the hydrophobic faces of the residues Trp275 and Trp397 stack against the heterocyclic rings of the reducing-end sugar units $(+1$ NAG and $+2 \mathrm{NAG}$; blue, Fig. 1a, b). We previously suggested that both residues are important for the primary interaction with soluble substrates [35]. We shall discuss later, in this study, that $\operatorname{Trp} 275$ and $\operatorname{Trp} 397$ are also crucial for the progressive degradation of insoluble chitin.

The structure in Fig. 1b also displays the cleavage site that is located between sites -1 and +1 (red arrow). Following the retaining mechanism, further cleavage would be expected to yield only $\beta \mathrm{NAG}_{4}$ and $\beta \mathrm{NAG}_{2}$. The released $\mathrm{NAG}_{4}$ had two fates. It may diffuse into the reaction mixture and then rebind or it may slide forward to accommodate the next cleavage if remained attached to the active site. On the other hand, $\mathrm{NAG}_{2}$ would dissociate from the product side $(+1$ and +2$)$ and serves as the end product of hydrolysis.
(A)

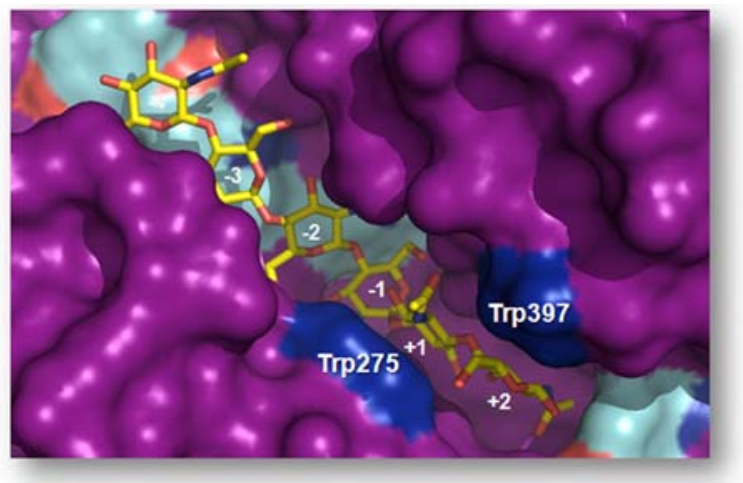

(B)

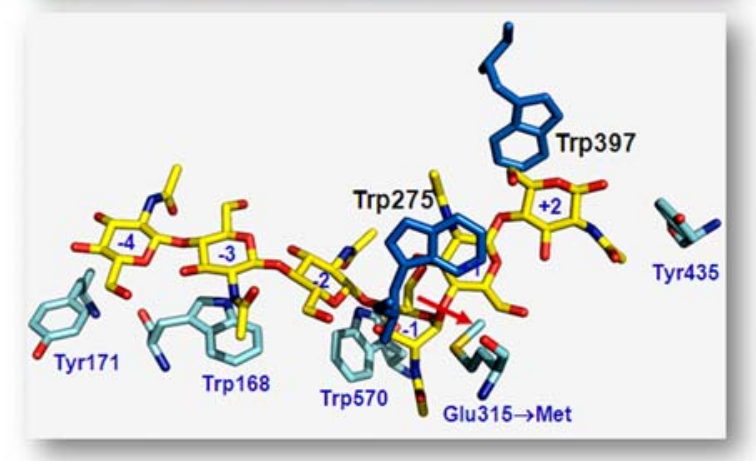

Fig. 1 The active site of $V$. harveyi chitinase A mutant E315M bound to hexaNAG. a A surface representation of hexaNAG that fully occupied subsites -4 to +2 within the substrate binding cleft of the enzyme. The sugar rings of $\mathrm{NAG}_{6}$ are shown in sticks. b A stick model of the binding cleft of chitinase A mutant E315M complexed with $\mathrm{NAG}_{6} . \mathrm{N}$ atoms are shown in blue and $\mathrm{O}$ atoms in red. $\mathrm{C}$ atoms are in marine blue for the amino acid residues and in yellow for the sugar residues. The cleavage site is indicated by an arrow, and Trp 275 and Trp397 are represented in blue. The structure of $\mathrm{E} 315 \mathrm{M}+\mathrm{NAG}_{6}$ complex is obtained from the PDB data base (PDB code, 3B9A) [24] and displayed by the program PyMol (http://www.pymol.org/)

Investigation of the binding modes of soluble substrates

We employed quantitative HPLC MS to establish the binding modes of three substrates. Pursuing the idea of Uchiyama et al. [28] that chitooligosaccharides randomly enter the catalytic cleft of chitinase A, it is presumed that binding of the incoming sugar chain may begin at variable sites to allow various glycosidic bonds to be accessible to the cleavage site located between sites -1 to +1 . Figure $2 \mathrm{a}$ and $b$ represent three possibilities where soluble substrates could interact with the multiple binding subsites of the enzyme. For a $\mathrm{NAG}_{5}$ substrate, the binding may begin at site -4 and end at site +1 , leading to a complete formation of $\beta \mathrm{NAG}_{4}+\beta \mathrm{NAG}$ (Fig. 2a, bottom trace). Alternatively, the sugar chain may bind to subsites -3 to +2 , subsequently generating $\beta \mathrm{NAG}_{3}+\beta \mathrm{NAG}_{2}$ (Fig. 2a, middle trace) or only four units of $\mathrm{NAG}_{5}$ bind to subsites -2 to +2 , leaving the reducing-end NAG unbound at the exterior of the substrate binding cleft. As a result, $\beta \mathrm{NAG}_{2}$ and either equilibrium ratio of $\beta / \alpha \mathrm{NAG}_{3}$ are expected (Fig. 2a, top trace). 
(A)

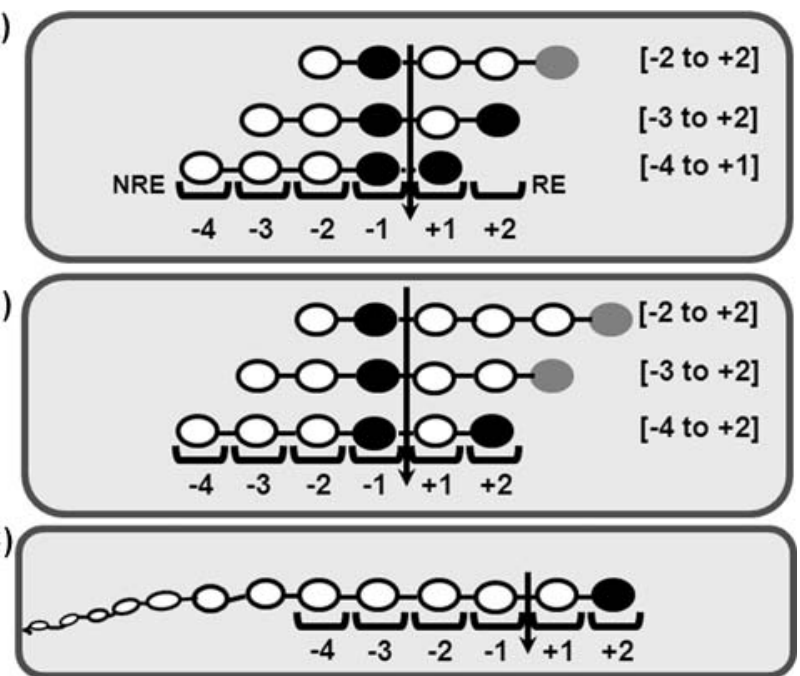

Fig. 2 Three possible models of chitin oligosaccharide bindings to the multiple binding subsites of $V$. harveyi chitinase A. Hydrolysis of a $\mathrm{NAG}_{5}, \mathbf{b} \mathrm{NAG}_{6}$, and $\mathbf{c}$ crystalline $\alpha$ chitin. NAG unit with $\beta$ configuration is shown in black circle, and NAG residue with $\alpha$ or $\beta$ configuration with an equilibrium ratio is shown in gray circle. Types of the reducing-end anomers are predicted based on the retaining mechanism as suggested for family-18 chitinases

With respect to a $\mathrm{NAG}_{6}$ substrate, it could interact with subsites $(-4$ to +2$)$. This binding mode is seen in the structure of $\mathrm{E} 315 \mathrm{M}+\mathrm{NAG}_{6}$, as shown in Fig. 1. The binding leads to a full occupancy of the six binding sites by chitohexaose (Fig. 2b, bottom trace). Subsequent bond cleavage results in the formation of $\beta \mathrm{NAG}_{4}+\beta \mathrm{NAG}_{2}$, where $\beta \mathrm{NAG}_{2}$ is released from the reducing-end subsites +1 to +2 . A different binding event takes place when five units of $\mathrm{NAG}_{6}$ bind to positions ( -3 to +2 ) (Fig. 2 b, middle trace), leaving the reducing-end NAG lying empty beyond the substrate binding cleft. As a result, a single cleavage of $\mathrm{NAG}_{6}$ leads to the formation of two $\mathrm{NAG}_{3}$, one of which (the non-reducing end $\mathrm{NAG}_{3}$ ) initially adopts $\beta$ configuration, while the other $\mathrm{NAG}_{3}$ possesses either $\beta$ or $\alpha$ configuration. A third version of binding is that four units of $\mathrm{NAG}_{6}$ symmetrically interact with subsites $(-2$ to +2$)$, thereby letting the reducing-end $\mathrm{NAG}_{2}$ remain unbound (Fig. 2b, top trace). This $(-2$ to +2$)$ binding mode releases $\beta \mathrm{NAG}_{2}$ from subsites ( -2 and -1 ), whereas $\beta$ or $\alpha \mathrm{NAG}_{4}$ is formed from the reducing-end side.

Assuming that the feeding mechanism is applicable, the binding characteristic of polymeric substrate is then depicted as Fig. 2c. After cleavage, a chitin chain remains attached to the active site before subsequently sliding forward toward the product side $(+1$ and +2$)$, thereby allowing $\mathrm{NAG}_{2}$ to be generated at a time. To investigate the preferred binding subsites of $V$. harveyi chitinase $\mathrm{A}, \mathrm{NAG}_{5}$ and $\mathrm{NAG}_{6}$ (as a representative of soluble chitin) were partially hydrolyzed by the enzyme and the reaction mixtures analyzed immediately by HPLC MS. Partial hydrolysis of the two substrates was carried out at $0{ }^{\circ} \mathrm{C}$ to stabilize the $\beta$ and $\alpha$ isomers of initial products. For the assignment of the HPLC elution of $\alpha$ and $\beta$ anomers acquired by our system, we referred to a separation profile of chitooligosaccharides obtained by reverse-phase HPLC and ${ }^{1}$ H-NMR [39]. Figure 3 represents an HPLC MS separation of chitin intermediates derived from partial hydrolysis of $\mathrm{NAG}_{6}$. The $\beta$ and $\alpha$ forms of an individual sugar were eluted at different retention times as a doublet. The preceding peak of the doublet is identified as $\beta$ and the following peak $\alpha$. Further mass detection by ESI-MS assigned $\mathrm{m} / \mathrm{z}$ values of the two isomers of the same sugar to be identical. For instance, $\mathrm{m} / \mathrm{z} 424.5$ was seen for $\beta \alpha \mathrm{NAG}_{2}, 627.5$ for $\beta \alpha \mathrm{NAG}_{3}, 830.3$ for $\beta \alpha \mathrm{NAG}_{4}$, and $1,236.5$ for $\beta \& \alpha \mathrm{NAG}_{6}$ (Fig. 3). Peak areas representing total ion counts of the corresponding oligomers were simply converted to molar concentrations using the standard calibration curves of $\mathrm{NAG}_{1-6}$.

From Fig. 3, V. harveyi chitinase A degraded $\mathrm{NAG}_{6}$, yielding $\beta \mathrm{NAG}_{2}+\beta \mathrm{NAG}_{3}$ as major isomers. This action was observed as early as $3 \mathrm{~min}$. On the other hand, $\beta \mathrm{NAG}_{4}$ and $\alpha \mathrm{NAG}_{4}$ were detected in comparable amounts, and $\mathrm{NAG}$ and $\mathrm{NAG}_{5}$ were not observed at all (Fig. 3). With $\mathrm{NAG}_{5}$ hydrolysis, two predominant products $\left(\beta \mathrm{NAG}_{2}\right.$ $+\alpha \mathrm{NAG}_{3}$ ) were captured during the initial time (data not shown). No other product was seen. The preferred binding modes of the enzyme toward $\mathrm{NAG}_{5}$ and $\mathrm{NAG}_{6}$ were determined by comparing $\beta$ content to $\alpha$ content of the same product (Table 1). The $\beta$ contents of $\mathrm{NAG}_{2}, \mathrm{NAG}_{3}$, and $\mathrm{NAG}_{4}$ obtained from $\mathrm{NAG}_{6}$ hydrolysis were estimated as $90 \%, 65 \%$, and $46 \%$, respectively (Table 1, wild type). Such values do not at all fit with the $\beta / \alpha$ ratios calculated by a single binding mode as presented in Fig. $2 b$. Apparently, the values agree well with the values (data in

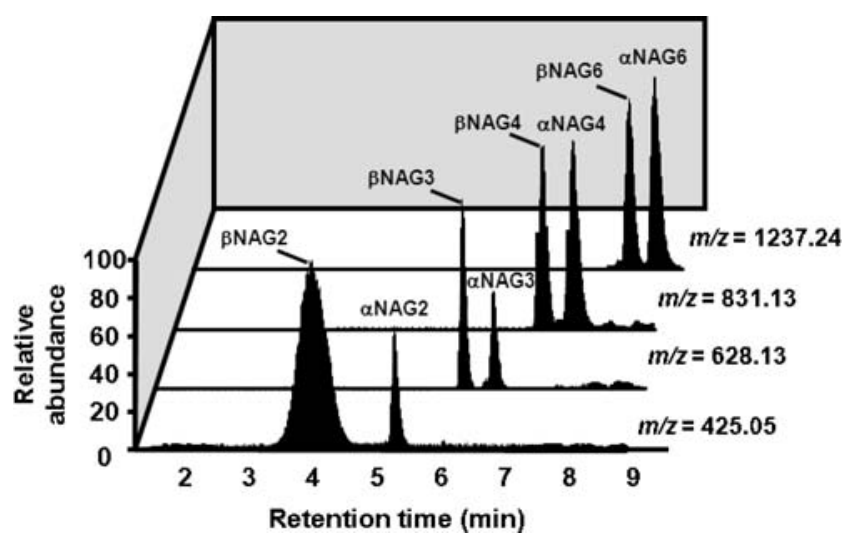

Fig. 3 An HPLC MS profile of the initial products obtained from partial hydrolysis of NAG6 by wild-type chitinase A. The hydrolytic reaction $(50 \mu \mathrm{L})$ was carried out on ice to minimize the rate of mutarotation. After $3 \mathrm{~min}$, aliquots of $10 \mu \mathrm{L}$ of the reaction mixture were subjected to HPLC MS analysis 
Table 1 Quantitative HPLC MS analysis of partial hydrolysis of chitooligosaccharides

\begin{tabular}{|c|c|c|c|c|c|c|c|}
\hline \multirow[t]{2}{*}{ Substrate } & \multirow[t]{2}{*}{ Enzyme } & \multicolumn{6}{|c|}{$\beta$ content of initial products } \\
\hline & & $\mathrm{NAG}_{1}$ & $\mathrm{NAG}_{2}$ & $\mathrm{NAG}_{3}$ & $\mathrm{NAG}_{4}$ & $\mathrm{NAG}_{5}$ & $\mathrm{NAG}_{6}$ \\
\hline \multirow[t]{3}{*}{ pentaNAG (NAG5) } & Wild-type & n.d. ${ }^{\mathrm{a}}$ & $90 \pm 4.1(100)^{\mathrm{b}}$ & $42 \pm 2.3(42)$ & n.d. & - & - \\
\hline & W275G & n.d. & $93 \pm 3.3$ & $68 \pm 9.2$ & n.d. & - & - \\
\hline & W397F & $81 \pm 6.0$ & $69 \pm 1.6$ & $98 \pm 1.2$ & $96 \pm 1.5$ & - & - \\
\hline \multirow[t]{3}{*}{ hexaNAG (NAG6) } & Wild type & n.d. & $90 \pm 2.2(100)^{\mathrm{c}}$ & $65 \pm 3.0(71)$ & $46 \pm 3.7(48)$ & - & - \\
\hline & W275G & n.d. & $92 \pm 4.9$ & $63 \pm 0.7$ & $79 \pm 2.8$ & - & - \\
\hline & W397F & n.s. ${ }^{\mathrm{d}}$ & $66 \pm 3.1$ & $95 \pm 9.5$ & $91 \pm 8.4$ & $96 \pm 1.8$ & - \\
\hline \multirow[t]{3}{*}{ Crystalline $\alpha$ chitin } & Wild type & n.d. & $87 \pm 1.5(100)^{\mathrm{e}}$ & $50 \pm 1.3$ (n.d.) & $42 \pm 1.0($ n.d) & $37 \pm 0.9$ (n.d.) & $46 \pm 4.5$ (n.d.) \\
\hline & W275G & n.d. & $88 \pm 1.2$ & $48 \pm 2.2$ & $56 \pm 3.2$ & $49 \pm 5.8$ & $50 \pm 3.7$ \\
\hline & W397F & n.s. & $88 \pm 2.1$ & $46 \pm 1.2$ & $57 \pm 3.4$ & $57 \pm 1.4$ & $51 \pm 2.0$ \\
\hline
\end{tabular}

A reaction mixture $(50 \mu \mathrm{L})$, containing chitin substrates and chitinase A in $0.1 \mathrm{M}$ ammonium acetate buffer, $\mathrm{pH} 7.0$, was incubated on ice and then analyzed by HPLC ESI/MS after 3 min. The $\beta$ contents were deduced from the peak areas of the corresponding products.

${ }^{a}$ n.d. represents product is not detectable

${ }^{\mathrm{b}}$ The values in brackets are the expected values from the -2 to -2 binding mode for NAG5 hydrolysis

${ }^{\mathrm{c}}$ The values in brackets are the expected values from a combination of the -3 to +2 and -2 to +2 modes for NAG6 hydrolysis

${ }^{d}$ n.s. represents non-separable between $\beta$ and $\alpha$ anomer. The initial $\beta$ contents were estimated from three independent sets of the experiment

${ }^{\mathrm{e}}$ The value is predicted from the progressive degradation of insoluble chitin

brackets, Table 1) derived from a combination of the -2 to +2 and -3 to +2 binding modes (top and middle traces, Fig. 2b). For $\mathrm{NAG}_{5}$ hydrolysis, the $\beta$ contents of $\mathrm{NAG}_{2}$ and $\mathrm{NAG}_{3}$ products were predicted as $90 \%$ and $42 \%$. These values are consistent with a single -2 to +2 binding mode (top trace, Fig. 2a). When the hydrolytic reactions were performed at equilibrium $\left(25^{\circ} \mathrm{C}\right.$, overnight), the predominating form of all the sugars was $\alpha$. The equilibrium $\beta$ contents were calculated as $48 \%$ for $\mathrm{NAG}_{2}, 42 \%$ for $\mathrm{NAG}_{3}$, $41 \%$ for $\mathrm{NAG}_{4}, 39 \%$ for $\mathrm{NAG}_{5}$, and $43 \%$ for $\mathrm{NAG}_{6}$ (data not shown).

Substrate binding preference toward crystalline $\alpha$ chitin

The substrate binding mode of natural substrate was further investigated. Figure $4 \mathrm{a}$ represents a time course of the hydrolytic products generated from crystalline $\alpha$ chitin hydrolysis by the wild-type chitinase. Similar to previous findings [20,34], $\mathrm{NAG}_{6}$ was degraded by $V$. harveyi chitinase $\mathrm{A}$, yielding $\mathrm{NAG}_{2}$ major products. Other intermediates $\left(\mathrm{NAG}_{3-6}\right)$ were also detected in the reaction mixture as early as $3 \mathrm{~min}$ although in much lower concentrations. The major isomer of $\mathrm{NAG}_{2}$ products was found to be $\beta$, while other products gave equilibrium ratios of $\alpha / \beta$ (Table 2). $\mathrm{NAG}_{2}$ was released at least sevenfold greater than the other products over the entire range of reaction times (Fig. 4a), indicating that the enzymatic cleavage preferably took place at the second bond from the chain ends. Nevertheless, the peaks corresponding to $\mathrm{NAG}_{3-6}$ that were detected in the reaction mixture simultaneously with $\mathrm{NAG}_{2}$ verified the existence of a random attack occurring at internal points of a chitin chain.

The cleavage feature of a long-chain chitin was further elucidated. The values shown in Fig. $4 \mathrm{~b}$ represent the cleavage ratios of $\mathrm{NAG}_{2}$ to $\mathrm{NAG}_{3}-\mathrm{NAG}_{6}$. These values were compared when the reaction was carried out at initial time (3 min) and at equilibrium (180 min). In all cases, the cleavage ratios $\mathrm{NAG}_{2}$ to other sugars were found to increase when the reactions reached equilibrium. For $\mathrm{NAG}_{2} / \mathrm{NAG}_{3}$, the ratio was enhanced by 1.5 times, for $\mathrm{NAG}_{2} / \mathrm{NAG}_{4}$ by nine times, for $\mathrm{NAG}_{2} / \mathrm{NAG}_{5}$ by five times, and for $\mathrm{NAG}_{2} / \mathrm{NAG}_{6}$ by six times. The lower cleavage ratios obtained at $3 \mathrm{~min}$ inferred that the internal attack proceeded at an early stage of reaction. The increased ratios represent the progressive action that took place at later time (i.e., at equilibrium).

Effects of point mutations on substrate bindings

Our recent data displayed a significant change in the cleavage patterns of $\mathrm{NAG}_{4}-\mathrm{NAG}_{6}$ hydrolysis when Trp275 was mutated to Gly and $\operatorname{Trp} 397$ to Phe. The 3D structure of chitinase A mutant $\mathrm{E} 315 \mathrm{M}$ bound to $\mathrm{NAG}_{6}$ has located $\operatorname{Trp} 275$ at the main subsites -1 , and +1 , and $\operatorname{Trp} 397$ at subsite +2 (Fig. 1a, b, blue). Alterations of the cleavage pattern as a result of Trp275 and Trp397 mutations provided a hint that both residues are important in defining the primary binding of soluble substrates [35]. In this study, we explored further how Trp275 and Trp397 influenced the binding selectivity of the enzyme. When incubated briefly, 


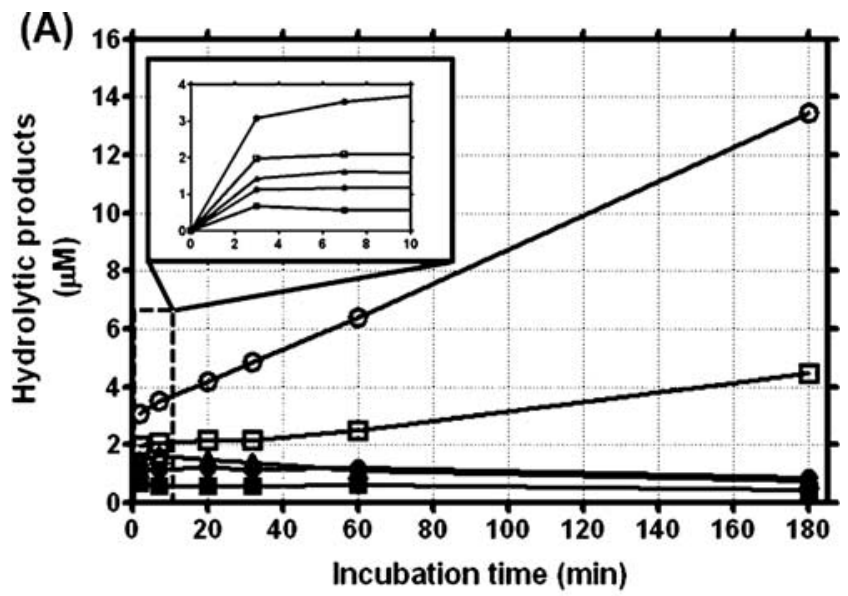

(B) $\quad=3 \mathrm{~min}=180 \mathrm{~min}$

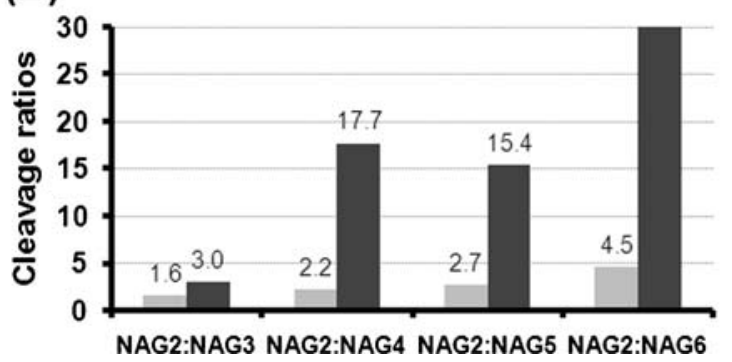

Fig. 4 Partial hydrolysis of crystalline $\alpha$ chitin by the wild-type chitinase A. a Time course of chitin hydrolysis. The hydrolytic reactions were carried out at on ice $\left(0{ }^{\circ} \mathrm{C}\right)$ from 0 to $180 \mathrm{~min}$ and were analyzed immediately by HPLC MS. Molar concentrations of the hydrolytic products were estimated using the standard curves of $\mathrm{NAG}_{1-6}$. b The cleavage ratios of $\mathrm{NAG}_{2} / \mathrm{NAG}_{3-6}$ were calculated based on the molar concentration of each corresponding sugar. The reaction products generated during $0-10 \mathrm{~min}$ are indicated as an inset. Open circle dimers, open square trimers, open triangle tetramers; filled circle pentamers, filled square and hexamers

the mutant $\mathrm{W} 275 \mathrm{G}$ was found to degrade $\mathrm{NAG}_{5}$ into $\mathrm{NAG}_{2}$ $+\mathrm{NAG}_{3}$ with the value of $\beta \mathrm{NAG}_{2}(93 \%)$ indistinguishable to the one formed by the wild-type enzyme (90\%) (Table 1). However, the $\beta$ content of $\mathrm{NAG}_{3}$ (68\%) produced by the mutated enzyme significantly increased when compared with the same product produced by the wild-type enzyme $(42 \%)$. With mutant W397F, the initial products of $\mathrm{NAG}_{5}$ hydrolysis by W397F were more varied from NAG to $\mathrm{NAG}_{4}$. The major form of all the products produced by W397F was $\beta$ with observed values of $81 \%$ for $\beta \mathrm{NAG}$, $69 \%$ for $\beta \mathrm{NAG}_{2}, 98 \%$ for $\beta \mathrm{NAG}_{3}$, and $96 \% \beta \mathrm{NAG}_{4}$ (Table 1).

Partial hydrolysis of $\mathrm{NAG}_{6}$ by mutant $\mathrm{W} 275 \mathrm{G}$ generated three product species $\left(\mathrm{NAG}_{2}+\mathrm{NAG}_{3}+\mathrm{NAG}_{4}\right)$, all having $\beta$ major isomer. The percentages of $\beta \mathrm{NAG}_{2}(92 \%)$ and $\mathrm{NNAG}_{3}(63 \%)$ were not similar to the wild-type value (Table 1). However, $\beta_{N_{A G}}$ formed by W275G (79\%) was significantly greater than $\beta \mathrm{NAG}_{4}$ formed by wild type (46\%). Similarly, $\mathrm{NAG}_{6}$ hydrolysis by mutant W397F released a full range of reaction intermediates (NAG-
$\left.\mathrm{NAG}_{5}\right)$. The $\beta$ contents for $\mathrm{NAG}_{2}(66 \%), \mathrm{NAG}_{3}(95 \%)$, and $\mathrm{NAG}_{4}(91 \%)$ were found to be different from that obtained from the non-mutated enzyme (Table 1).

Effects of point mutations on the kinetic properties

The steady-state kinetics of the hydrolytic activity of wildtype chitinase A and mutants W275G and W397F were investigated by using the DNS reducing-sugar assay (see "Experimental"). Table 2 represents the kinetic values of the three chitinase variants against $\mathrm{NAG}_{5}, \mathrm{NAG}_{6}$, and crystalline chitin. With $\mathrm{NAG}_{5}$ hydrolysis, the $K_{\mathrm{m}}$ of W275G $(315 \mu \mathrm{M})$ was only slightly decreased, but the $K_{\mathrm{m}}$ of W397F $(476 \mu \mathrm{M})$ was 1.25 -fold elevated from the $K_{\mathrm{m}}$ of wild type $(380 \mu \mathrm{M})$. Similar results were observed with $\mathrm{NAG}_{6}$ hydrolysis, where the $K_{\mathrm{m}}$ of $\mathrm{W} 275 \mathrm{G}(238 \mu \mathrm{M})$ was twofold lower, whereas the $K_{\mathrm{m}}$ of W397F $(460 \mu \mathrm{M})$ was 2.6 -fold greater than the $K_{\mathrm{m}}$ of wild type $(174 \mu \mathrm{M})$.

Mutations of Trp275 and Trp397exhibited a more severe effect on the catalytic constant $\left(k_{\mathrm{cat}}\right)$ of the enzyme. With the $\mathrm{NAG}_{5}$ substrate, the $k_{\text {cat }}$ of W275G $\left(0.04 \mathrm{~s}^{-1}\right)$ was fivefold lower than that of wild type $\left(0.21 \mathrm{~s}^{-1}\right)$. In contrast, the $k_{\text {cat }}$ of W397F $\left(2.1 \mathrm{~s}^{-1}\right)$ was tenfold higher. Similar results were seen with the $\mathrm{NAG}_{6}$ substrate by which W275G $\left(0.06 \mathrm{~s}^{-1}\right)$ showed a threefold decrease, but W397F displayed a 16 -fold increase in the $k_{\text {cat }}$ compared to that of wild type $\left(0.19 \mathrm{~s}^{-1}\right)$.

Both mutations gave a different outcome on insoluble substrate. The $K_{\mathrm{m}}$ of $\mathrm{W} 275 \mathrm{G}\left(25 \mathrm{mg} \mathrm{mL}^{-1}\right)$ and $\mathrm{W} 397 \mathrm{~F}$ $\left(19 \mathrm{mg} \mathrm{mL}^{-1}\right)$ toward colloidal chitin were higher than that of wild type $\left(12 \mathrm{mg} \mathrm{mL}^{-1}\right)$. Both mutants displayed a $0.3-$ 0.5 -fold loss in the $k_{\text {cat }}$. The $k_{\text {cat }} / K_{\mathrm{m}}$ values of $\mathrm{W} 275 \mathrm{G}$ toward all substrates were decreased five times toward $\mathrm{NAG}_{5}$ and $\mathrm{NAG}_{6}$ but ten times toward the crystalline chitin. In contrast, the $k_{\mathrm{cat}} / K_{\mathrm{m}}$ values of W397F toward the short-chain substrates were increased by six- to eightfold but a fivefold decrease toward the long-chain chitin.

Effects of point mutations on the anomer selectivity

The effects of $\operatorname{Trp} 275$ and $\operatorname{Trp} 397$ mutations on the anomer selectivity of the oligosaccharide hydrolysis were further investigated. Determination of substrate decrease at different time points revealed that the wild-type enzyme degraded both $\beta$ and $\alpha$ anomers at equal rates (Fig. 5a). However, the initial rate of the depletion of $\beta \mathrm{NAG}_{5}$ by W275G (Fig. 5a) occurred about 1.4 times faster than the rate of $\alpha \mathrm{NAG}_{5}$ depletion. At 155 min of incubation, only half of $\alpha \mathrm{NAG}_{5}$, but all of $\beta \mathrm{NAG}_{5}$, was degraded. $\beta \mathrm{NAG}_{5}$ was also utilized by mutant W397F at a significantly higher rate than $\alpha \mathrm{NAG}_{5}$; however, the anomer consumption varied linearly over time of incubation (Fig. 5b). At the end of reaction, a substantial amount of $\alpha \mathrm{NAG}_{5}(>50 \%)$ and only 

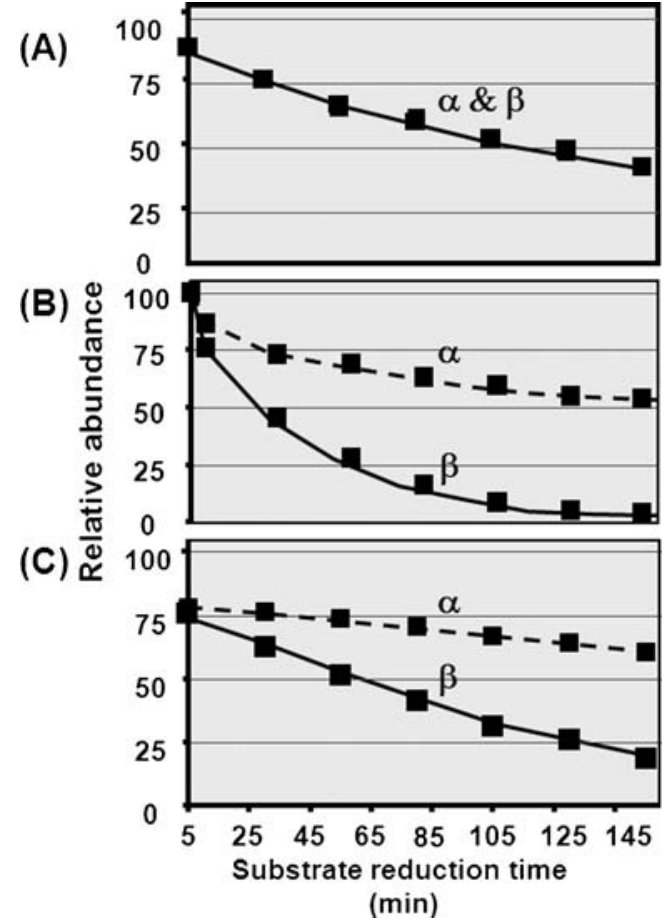

Fig. 5 Time-course of substrate consumption by chitinase A. Hydrolysis of $\mathrm{NAG}_{5}$ by a wild type, b mutant W275G, and $\mathbf{c}$ mutant W397F. The hydrolytic reactions carried out at on ice $\left(0{ }^{\circ} \mathrm{C}\right)$ from 0 to 155 min were analyzed by HPLC ESI/MS as described in texts. Rate of $\beta$ anomer consumption is presented by a black line and rate of $\beta$ anomer consumption by a broken line

a small amount of $\beta \mathrm{NAG}_{5}(<20 \%)$ remained in the reaction mixture.

With the $\mathrm{NAG}_{6}$ substrate, similar patterns were observed (data not shown). The wild-type enzyme displayed no preferable selection toward a particular anomer of $\mathrm{NAG}_{6}$. However, the initial rates of $\beta \mathrm{NAG}_{6}$ degradation by both mutants were only slightly higher than that of $\alpha \mathrm{NAG}_{6}$ consumption. At the final stage of reaction, most of $\beta \mathrm{NAG}_{5}$ and $\beta \mathrm{NAG}_{6}(>80 \%)$ was used up.

\section{Discussion}

The 3D structures of the catalytically inactive mutant E315M complexed with $\mathrm{NAG}_{5}$ and $\mathrm{NAG}_{6}$ suggested that $V$. harveyi chitinase A most likely catalyzed chitin degradation through the 'slide and bend' mechanism [27]. From the mechanistic point of view, the sliding process can only be achieved by an enzyme with high processivity. Eijsink and colleagues reported previously that ChiA, ChiB, and ChiC from $S$. marcescens possessed different degrees of processivity $[19,29,30]$. ChiA was tested to be more processive than $\mathrm{ChiB}$, whereas $\mathrm{ChiC}$ is a nonprocessive enzyme. The processive property explains how an enzyme processes it substrates. However, the mechanism 
of how each substrate initially interacts with the enzyme depends entirely on the size of its substrate. Chitin oligomers are predicted to bind to the substrate-binding cleft by a random fashion. It implies that the sugar oligomer has freedom to bind to variable sites as far as the successful cleavage is concerned. In this study, three models are proposed for the productive binding of the soluble substrates (Fig. 1). $\mathrm{NAG}_{5}$ may interact either with subsites $(-4$ to +1$),(-3$ to +2$)$, or $(-2$ to +2$)$ (Fig. 2a). Likewise, $\mathrm{NAG}_{6}$ may bind to subsites ( -4 to +2$),(-3$ to +2$)$, or $(-2$ to +2) (Fig. 2b).

HPLC MS analysis of $\mathrm{NAG}_{6}$ hydrolysis by wild-type chitinase gave rise to three species of reaction products $\left(\mathrm{NAG}_{2,3,4}\right)$. This happens only when the glycosidic cleavage takes place at least at two distinct locations. The presence of $\mathrm{NAG}_{3}$ in the reaction mixture (Table 1) suggested that the enzymatic cleavage occurred in the middle of the chitin hexamer. When initial isomers of the degradation products were trapped at very low temperature $\left(0{ }^{\circ} \mathrm{C}\right)$ for a short period of time $(3 \mathrm{~min})$, the estimated $\mathrm{NNAG}_{3}(65 \%)$ agreed best to that of $\mathrm{NAG}_{3}$ expected from the $(-3$ to +2$)$ binding mode $(71 \%)$ (the value in brackets, Table 1). Two other products $\left(\mathrm{NAG}_{2}\right.$ and $\left.\mathrm{NAG}_{4}\right)$ could otherwise come from the interactions at subsites -4 to +2 or -2 to +2 . However, the measured percentages of $\beta \mathrm{NAG}_{2}$ $(90 \%)$ and $\mathrm{BNAG}_{4}(46 \%)$ were in conflict with the calculated values for the (-4 to +2$)$ binding mode $(100 \%$ for both $\beta \mathrm{NAG}_{2}$ and $\beta \mathrm{NAG}_{4}$ ). Instead, the obtained values agreed well with the $100 \% \beta \mathrm{NAG}_{2}$ and $48 \% \mathrm{NAG}_{4}$ as calculated for the $(-2$ and +2$)$ binding mode (Fig. 2b). This experimental outcome suggests binding of the chitin hexamer to either subsites -3 to +2 or -2 to +2 , which emphasizes a dynamic process of interaction between an active enzyme and the substrate, and is in contrast with the occupation of the oligomer as observed in the static complex of the inactive enzyme (Fig. 1a, b). Previous quantitative HPLC MS analysis estimated the yield of $\mathrm{NAG}_{3}$ to be 4 nmol when $\mathrm{NAG}_{6}$ was incubated with native chitinase A for $5 \mathrm{~min}$. This yield was half of $\mathrm{NAG}_{2}+\mathrm{NAG}_{4}$ yields ( $\sim 8 \mathrm{nmol})$ obtained from the same reaction [34], and it indicated that $\mathrm{NAG}_{6}$ favors the $(-2$ to +2$)$ mode over the $(-3$ to +2$)$ mode.

Limited hydrolysis of $\mathrm{NAG}_{5}$ yielded only two products $\left(\mathrm{NAG}_{2}+\mathrm{NAG}_{3}\right)$, meaning that the bond cleavage took place only at a single site either at positions -3 to +2 or -2 to +2 (see Fig. 2A). However, the observed percentages of $\beta \mathrm{NAG}_{2}(90 \%)$ and $\beta \mathrm{NAG}_{3}(42 \%)$ agreed more to that of $\beta \mathrm{NAG}_{2}(100 \%)$ and $\beta \mathrm{NAG}_{3}(42 \%)$ predicted for the (-2 to +2 ) binding mode. In contrast, $100 \% \beta \mathrm{NAG}_{2}$ and $100 \%$ $\mathrm{NAG}_{3}$ would be expected from the $(-3$ to +2$)$ binding mode. No detection of NAG and $\mathrm{NAG}_{4}$ in the reaction mixture implied that the $(-4$ to +1$)$ mode was completely ignored by this substrate (see Table 1).
The binding characteristics of $S$. marcescens Chi A [40] and Coccidioides immitis chitinase-1 (CiX1) [41] were previously investigated by means of typical HPLC systems. Hydrolysis of $\mathrm{NAG}_{6}$ by SmChiA that yielded $99 \% \beta \mathrm{NAG}_{2}$, $71 \% \mathrm{NAG}_{3}$ and $48 \% \mathrm{NAG}_{4}$ and hydrolysis of $\mathrm{NAG}_{5}$ that yielded $100 \% \beta \mathrm{NAG}_{2}$ and $55 \% \beta_{\mathrm{NAG}_{3}}$ represents the equivalent binding events as observed in this study. In CiX1, formations of $\alpha / \beta \mathrm{NAG}_{2}(9 / 1)$ and $\alpha / \beta \mathrm{NAG} 4(5 / 2)$ from NAG6 hydrolysis supports the $(-2$ to +2$)$ binding mode. Sasaki et al. [42] performed a comparative study of the reaction mechanism of rice and bacterial enzymes and concluded that microbial chitinases favors the $(-2)(-1)(+1)$ $(+2)(+3)(+4)$ subsites, while plant chitinases prefers the $(-4)(-3)(-2)(-1)(+1)(+2)$ subsites. Binding of a chitooligomer to $(-2)$ to $(+4)$ sites would be comparable to the -2 to +2 binding mode described for $V$. harveyi chitinase A.

With partial hydrolysis of insoluble chitin, $\mathrm{NAG}_{2}$ observed as the primary product during the course of reaction (from 0 to $180 \mathrm{~min}$ ) was mostly derived from the progressive degradation of the second bond from a chain end of chitin polymer. Imai et al. [33] demonstrated previously that the degradation of $\beta$ chitin microfibrils took place from the reducing end of the sugar chain. However, other products $\left(\mathrm{NAG}_{3-6}\right)$ that were observed in the reaction mixture, even as early as $3 \mathrm{~min}$, and the equilibrium ratios of $\mathrm{NAG}_{3-6}$ products obtained from a long-chain chitin hydrolysis (Table 1) were an indication of internal attacks that took place at variable positions within the chitin chain. This interpretation is further supported by the small cleavage ratios of $\mathrm{NAG}_{2} / \mathrm{NAG}_{3-6}$ intermediates. A dramatic increase in the ratios at later time of reaction is presumably achieved quite productively with the progressive action via the feeding and sliding mechanism.

The anomer analysis revealed no selectivity of the wildtype chitinase A in utilization of $\alpha$ or $\beta$ substrates (Fig. 5a). No selectivity of binding by all means leaves the enzyme a lot more freedom to efficiently take up the $\beta$ or $\alpha$ substrates that are present in the reaction equilibrium. This idea is well complimented by binding of $\mathrm{NAG}_{5}$ to subsites $(-2$ to +2$)$ and $\mathrm{NAG}_{6}$ to subsites $(-3$ to +2$)$ or $(-2$ to +2$)$ as seen in Fig. $2 \mathrm{a}$ and $\mathrm{b}$. For the structural point of view, $V$. harveyi chitinase A is shown to comprise a substrate binding cleft with a long, deep groove structure (Fig. 1). The reducing end of the binding groove is shown to be open, giving adequate space for the incoming sugar chain to move beyond the +2 site. As a consequence, various glycosidic bonds are accessible to the cleavage site. The open-end active site certainly fits the binding preference of $\mathrm{NAG}_{5}$ and $\mathrm{NAG}_{6}$ and the endo action of the enzyme toward chitin polymers.

We previously reported that the residues $\operatorname{Trp} 275$ and Trp397 positioned at subsites $(-1,+1$, and +2 sites $)$ are particularly essential for defining the primary binding of 
soluble chitooligosaccharides and Trp70 located at the Nterminal end of the ChBD is crucial for insoluble chitin degradation $[35,43]$. In this study, the effects of mutations on the kinetic properties of the enzyme were evaluated. It was found that mutations of Trp275 and Trp397 to Gly and Phe, respectively, significantly changed the substrate specificity and the anomer selectivity of the enzyme. The structure of mutant $\mathrm{E} 315 \mathrm{M}$ bound to $\mathrm{NAG}_{6}$ showed that Trp275 could interact strongly with $-1 \mathrm{NAG}$ and $+1 \mathrm{NAG}$ [27]. Mutation of this residue was found to affect the kinetic properties involving the catalytic center by decreasing the $k_{\text {cat }}$ and the $k_{\text {cat }} / K_{\mathrm{m}}$ toward $\mathrm{NAG}_{5}$ and $\mathrm{NAG}_{6}$ by a magnitude of 5 (Table 2). In addition, the mutation significantly increased the apparent rate of $\beta$ consumption as shown in Fig. 5a. The event may be explained as a shift of the sugar chain toward the non-reducing end in the search for other available binding sites to compensate for the loss of interactions. The observed yields of $\beta \mathrm{NAG}_{2}$ $(93 \%)$ and $\beta_{N A G}(68 \%)$ obtained from the cleavage of $\mathrm{NAG}_{5}$ by $\mathrm{W} 275 \mathrm{G}$ (Table 1) agrees well with the predicted yields of $\beta \mathrm{NAG}_{2}(100 \%)$ and $\beta \mathrm{NAG}_{3}(42-100 \%)$ of the model shown in Fig. 6a. A single move of the sugar chain toward the non-reducing end is predicted as further movement would likely be blocked by high affinity of binding between the reducing end of $\mathrm{NAG}_{5}$ and Trp397 at subsite +2 .

Different situations were observed with mutant W397F. Mutation of Trp397 to Phe led to an increase in the $k_{\text {cat }}$ toward $\mathrm{NAG}_{5}$ and $\mathrm{NAG}_{6}$ by 10 - and16-fold, giving rise to an increase in the $k_{\text {cat }} / K_{\mathrm{m}}$ by a magnitude of 8 and 16 , respectively. $\operatorname{Trp} 397$ is a crucial binding residue located at subsite +2 , and it determines the primary binding of chitooligosaccharide substrates. A phenylalanine substitu- tion appeared to weaken the binding strength of this subsite, enabling the sugar chain to move more freely and allowing various glycosidic bonds to be exposed to the cleavage sites. A full range of reaction intermediates seen in the reaction mixture of W397F (Table 1) supports the above assumption. Hydrolysis of $\mathrm{NAG}_{5}$ by W397F, yielding $81 \%$ $\beta N A G, 69 \% \quad \beta \mathrm{NAG}_{2}, 98 \% \quad \beta \mathrm{NAG}_{3}$, and $96 \% \beta \mathrm{NAG}_{4}$ products agreed well with the yields proposed in Fig. 6 b.

The residues Trp275 and Trp397 are found to be important for insoluble chitin hydrolysis, since the mutations showed a remarkable decrease in the $k_{\text {cat }}$ value of the enzyme. The structure in Fig. 1 shows that both residues are located in a perfect position to be responsible for the feeding process by pulling the chitin chain toward the reducing end subsites, thereby permitting the next processive hydrolysis to occur (see Fig. 6c). A significant reduction of the $k_{\text {cat }}$ and the $k_{\text {cat }} / K_{\mathrm{m}}$ values toward colloidal chitin (Table 2) seems to support the proposed roles of both residues (Table 2). Similar effects were also reported with ChiA1 from B. circulans, where mutations of Trp164 (equivalent to Trp275) and Trp285 (equivalent to Trp397) drastically reduced the hydrolytic activity of their enzymes toward colloidal chitin by $40-50 \%$ [44].

In conclusion, we employed quantitative HPLC MS to determine the binding modes of a family-18 chitinase from $V$. harveyi toward three substrates. Neither a random nor a progressive binding was entirely employed for a complete hydrolysis of the tested substrates. Nevertheless, soluble chitins seem to favor the -2 to +2 binding, but insoluble chitin preferred the progressive binding. Mutations of $\operatorname{Trp} 275$ and Trp397 were found to affect the anomer selectivity and the substrate specificity toward soluble substrates. The evaluation of the kinetic data suggested
Fig. 6 Plausible effects of point mutation on the substrate binding preference and the anomer selectivity. Binding of $\mathrm{NAG}_{5}$ to a wild-type chitinase, b mutant W275G, and c mutant W397F. The $\beta$ configuration is shown in black circle, NAG residue with $\alpha$ or $\beta$ configuration with an equilibrium ratio is shown in gray circle, and NAG residue with $\alpha$ or $\beta$ configuration that binds to a loosen-affinity binding site is shown in gray-filled in dark circle. The cleavage site is indicated by an arrow

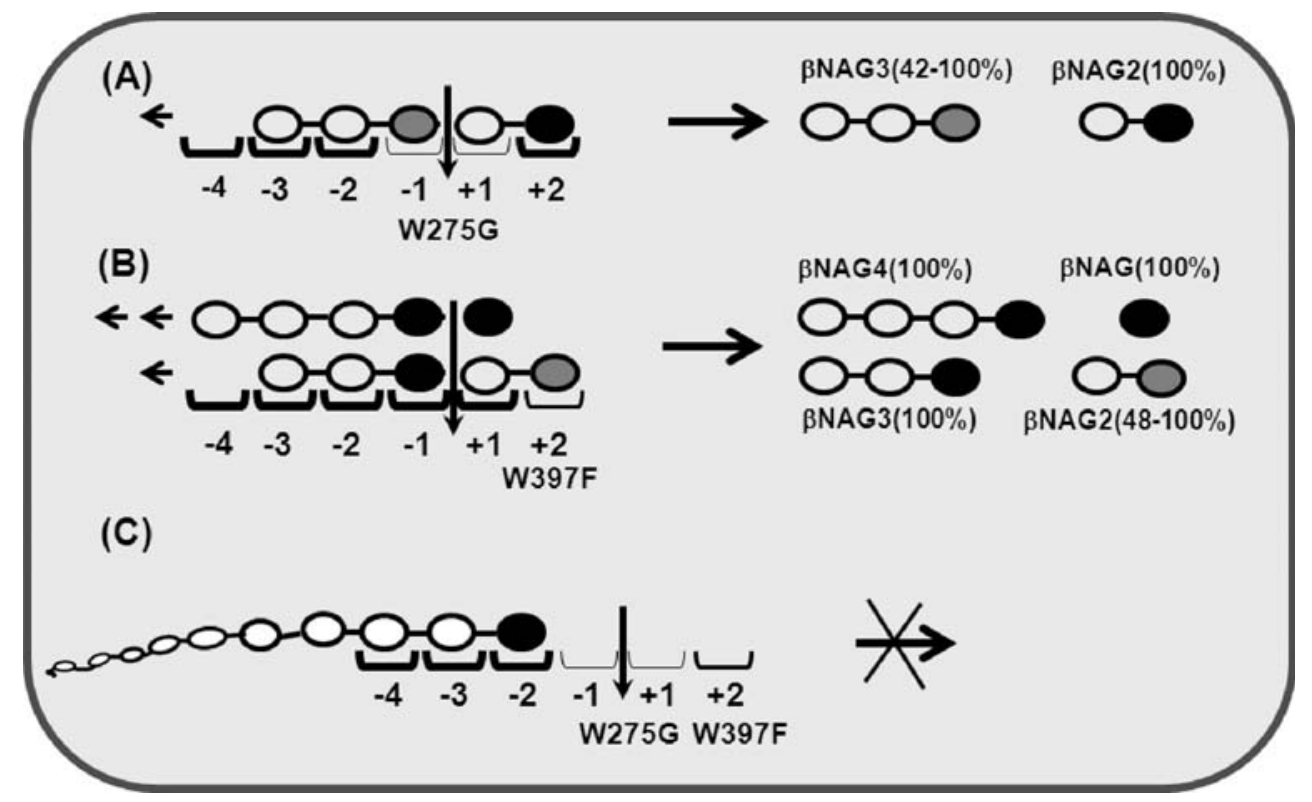


that Trp275 and Trp397 are likely involved in the feeding process that facilitates a degradation of chitin polymer in a progressive manner. Ultimately, understanding of the binding mechanism of family-18 chitinases to their substrates may aid the drug-screening program to obtain effective inhibitors that act as therapeutic candidates for successful treatment of allergic asthma.

Acknowledgements This work is financially supported by Suranaree University of Technology, The Thailand Research Fund and The Thai Commission on Higher Education through a Research Career Development Grant to WS (grant no. RMU4980028). The Thailand Research Fund through the Royal Golden Jubilee PhD Program (grant no. PHD/0238/2549) to SP and WS is acknowledged.

\section{References}

1. Hirono I, Yamashita M, Aoki T (1998) Note: molecular cloning of chitinase genes from Vibrio anguillarum and $V$. parahaemolyticus. J Appl Microbiol 84:1175-1178

2. Suginta W, Robertson PA, Austin B et al (2000) Chitinases from Vibrios: activity screening and purification of chi A from Vibrio carchariae. J Appl Microbiol 89:76-84

3. Keyhani NO, Roseman S (1999) Physiological aspects of chitin catabolism in marine bacteria. Biochim Biophys Acta 1473:108122

4. Merzendorfer H, Zimoch L (2003) Chitin metabolism in insects: structure, function and regulation of chitin synthases and chitinases. J Exp Biol 206:4393-4412

5. Herrera-Estrella A, Chet I (1999) Chitinases in biological control. EXS 87:171-184

6. Melchers LS, Stuiver MH (2000) Novel genes for diseaseresistance breeding. Curr Opin Plant Biol 3:147-152

7. Gooday GW, Zhu WY, O’Donnell RW (1992) What are the roles of chitinases in the growing fungus? FEMS Microbiol Lett 100:387-392

8. Wills-Karp M, Karp CL (2004) Chitin checking - novel insights into asthma. N Engl J Med 351:1455-1457

9. Kawada M, Hachiya Y, Arihiro A et al (2007) Role of mammalian chitinases in inflammatory conditions. Keio J Med 56:21-27

10. Zhu Z, Zheng T, Homer RJ et al (2004) Elias acidic mammalian chitinase in asthmatic Th2 inflammation and IL-13 pathway activation. Science 304:1678-1682

11. Watanabe T, Suzuki K, OyaGi W et al (1990) Gene cloning of chitinase A1 from Bacillus circulans WL-12 revealed its evolutionary relationship to Serratia chitinase and to the type III homology units of fibronectin. J Biol Chem 265:15659-15665

12. Jones JDG, Grady KL, Suslow TV et al (1986) Isolation and characterization of genes encoding two chitinase enzymes from Serratia marcescens. EMBO J 5:6467-6473

13. Roffey PE, Pemberton JM (1990) Cloning and expression of an Aeromonas hydrophila chitinase gene in Escherichia coli. Curr Microbiol 21:329-337

14. Sitrit Y, Vorgias CE, Chet I et al (1995) Cloning and primary structure of The chiA gene from Aeromonas caviae. J Bacteriol $177: 4187-4189$

15. Tsujibo H, Orikoshi H, Tanno H et al (1993) Cloning, sequence, and expression of a chitinase gene from a marine bacterium, Altermonas sp. strain O-7. J Bacteriol 175:176-181

16. Suginta W (2007) Identification of chitin binding proteins and characterization of two chitinase isoforms from Vibrio alginolyticus 283. Enzyme Microb Tech 41:212-220
17. Itoi S, Kanomata Y, Koyama Y et al (2007) Identification of a novel endochitinase from a marine bacterium Vibrio proteolyticus strain No. 442. Biochim Biophys Acta 1774:1099-1107

18. Suzuki K, Sugawara N, Suzuki M et al (2002) Chitinases A, B, and $\mathrm{C} 1$ of Serratia marcescens 2170 produced by recombinant Escherichia coli: enzymatic properties and synergism on chitin degradation. Biosci Biotechnol Biochem 66:1075-1083

19. Sikorski P, Sørbotten A, Horn SJ et al (2006) Serratia marcescens chitinases with tunnel-shaped substrate-binding grooves show endo activity and different degrees of processivity during enzymatic hydrolysis of chitosan. Biochemistry 45:95669574

20. Suginta W, Vongsuwan A, Songsiriritthigul C et al (2004) An endochitinase A from Vibrio carchariae: cloning, expression, mass and sequence analyses, and chitin hydrolysis. Arch Biochem Biophys 424:171-180

21. Perrakis A, Tews I, Dauter Z et al (1994) Crystal structure of a bacterial chitinase at $2.3 \AA$ resolution. Structure 2:1169-1180

22. Tews I, Terwisscha van Scheltinga AC, Perrakis A et al (1997) Substrate assisted catalysis unifies two families of chitinolytic enzymes. J Am Chem Soc 119:7954-7959

23. Terwisscha van Scheltinga AC, Armand S, Kalk KH et al (1995) Stereochemistry of chitin hydrolysis by a plant chitinase/lysozyme and X-ray structure of a complex with allosamidin: evidence for substrate assisted catalysis. Biochemistry 34:15619-15623

24. Hollis T, Monzingo AF, Bortone $\mathrm{K}$ et al (2000) The X-ray structure of a chitinase from the pathogenic fungus Coccidioides immitis. Protein Sci 9:544-551

25. Brameld KA, Goddard WA III (1998) Substrate distortion to a boat conformation at subsite -1 is critical in the mechanism of family 18 chitinases. J Am Chem Soc 120:3571-3580

26. Terwisscha van Scheltinga AC, Hennig M, Dijkstra BW (1996) The $1.8 \AA$ resolution structure of hevamine, a plant chitinase/ lysozyme, and analysis of the conserved sequence and structure motifs of glycosyl hydrolase family 18. J Mol Biol 262:243257

27. Songsiriritthigul C, Pantoom S, Aguda AH et al (2008) Crystal structures of Vibrio harveyi chitinase A complexed with chitooligosaccharides: implications for the catalytic mechanism. J Struct Biol 162:491-499

28. Uchiyama T, Katouno F, Nikaidou N et al (2001) Roles of the exposed aromatic residues in crystalline chitin hydrolysis by chitinase A from Serratia marcescens 2170. J Biol Chem 276:41343-41349

29. Sørbotten A, Horn SJ, Eijsink VG et al (2005) Degradation of chitosans with chitinase B from Serratia marcescens. Production of chitooligosaccharides and insight into enzyme processivity. FEBS J 272:538-549

30. Horn SJ, Sørbotten A, Synstad B et al (2006) Endo/exo mechanism and processivity of family 18 chitinases produced by Serratia marcescens. FEBS J 273:491-503

31. Boisset C, Fraschini C, Schülein M et al (2000) Imaging the enzymatic digestion of bacterial cellulose ribbons reveals the endo character of the cellobiohydrolase Cel6A from Humicola insolens and its mode of synergy with cellobiohydrolase Cel7A. Appl Environ Microbiol 66:1444-1452

32. Imai T, Boisset C, Samejima $M$ et al (1998) Unidirectional processive action of cellobiohydrolase Cel7A on Valonia cellulose microcrystals. FEBS Lett 432:113-116

33. Imai T, Watanabe T, Yui T, Sugiyama J (2002) Directional degradation of beta-chitin by chitinase A1 revealed by a novel reducing end labelling technique. FEBS Lett 510:201-205

34. Suginta W, Vongsuwan A, Songsiriritthigul C et al (2005) Enzymatic properties of wild-type and active site mutants of chitinase A from Vibrio carchariae, as revealed by HPLC-MS. FEBS J 272:3376-3386 
35. Suginta W, Songsiriritthigul C, Kobdaj A et al (2007) Mutations of Trp275 and Trp397 altered the binding selectivity of Vibrio carchariae chitinase A. Biochim Biophys Acta 1770:1151-1160

36. Laemmli UK (1970) Cleavage of structural proteins during the assembly of the head of bacteriophage T4. Nature 227:680-685

37. Bradford MM (1976) A rapid and sensitive method for the quantitation of microgram quantities of protein utilizing the principle of protein-dye binding. Anal Biochem 72:248-254

38. Miller GL (1959) Use of dinitrosalicylic acid reagent for determination of reducing sugar. Anal Chem 31:426-429

39. Armand S, Tomita H, Heyraud A et al (1994) Stereochemical course of the hydrolysis reaction catalysed by chitinase A1 and D from Bacillus circulans WL-12. FEBS Lett 343:177-180

40. Aronson NN Jr, Halloran BA, Alexyev MF et al (2003) Family 18 chitinase-oligosaccharide substrate interaction: subsite preference and anomer selectivity of Serratia marcescens chitinase A. Biochem J 376:87-95

41. Fukamizo T, Sasaki C, Schelp E et al (2001) Kinetic properties of chitinase-1 from the fungal pathogen Coccidioides immitis. Biochemistry 40:2448-2454

42. Sasaki C, Yokoyama A, Itoh Y et al (2002) Comparative study of the reaction mechanism of family 18 chitinases from plants and microbes. J Biochem 131:557-564

43. Pantoom S, Songsiriritthigul C, Suginta W (2008) The effects of the surface-exposed residues on the binding and hydrolytic activities of Vibrio carchariae chitinase A. BMC Biochem 9:2

44. Watanabe T, Ariga Y, Sato U et al (2003) Aromatic residues within the substrate-binding cleft of Bacillus circulans chitinase A1 are essential for hydrolysis of crystalline chitin. Biochem J $376: 237-244$ 